theless the chance of pregnancy is so slight that the need for practising contraception during menstruation is not very real. This is particularly true if the cycle lasts 28 days. The shorter the woman's cycle, and the later the day of the period at which coitus takes place, the greater the chance of conception.

The Bedroom of an Allergic Child

Q. -What non-allergic bedclothes are recommended for an allergic child? What other precautions should be taken to exclude possible allergens from his bedroom?

A.- The mattress and pillows should be of soft rubber latex foam. Cotton sheets and pillow cases and flannelette or woollen blankets are allowed. Exclusion of wool is only very occasionally advised or necessary. No eiderdown or other padded type of bedding is advised. Cotton sheets and pillow cases should be washed weekly and blankets laundered or dry-cleaned every two weeks or so.

It is also important to aim at a dust-free room. The floor should be bare or covered with linoleum and polished to give it a slightly sticky surface. Small washable rugs are permissible. Furniture and toys should be reduced to a minimum and special dusting with a damp cloth carried out every other day, especially of those areas where dust may accumulate and not be seen, such as on picture rails, tops of furniture, etc.

\section{Hydronephrosis in Pregnancy}

Q.-What proportion of pregnancies are associated with hydronephrosis of one or both sides? Does the renal condition return to normal after delivery? Please quote key references.

A.- Although some authorities say that dilatation of the renal pelvis and upper ureter occurs in some degree in all pregnancies the usually accepted figures are $85 \%$ of cases so far as the right urinary tract is concerned and 70-75\% for the left side. When it comes to minor degrees of dilatation there is clearly room for differences of opinion. The dilatation is more obvious in primigravidae than in multigravidae. It probably begins about the 6-10th week (some say 16 weeks) and reaches a maximum at 24 to 32 weeks (some say later). The classical papers on this subject in this country are those by D. Baird. ${ }^{2}$ A useful review of the literature, however, is published by D. H. Schneider et al. ${ }^{3}$ This mentions the first observation made more than 100 years ago and includes reference to experimental work in animals and women. Other articles are by G. C. Prather ${ }^{4}$ and H. L. Kretschmer. ${ }^{5}$ The last author deals particularly with the time after delivery at which the urinary tract returns to normal, and says that it does so within two weeks in $60 \%$ of cases, within six weeks in a further $34 \%$, and within twelve weeks in the remaining $6 \%$. Other observers have found the urinary tract normal within one week of delivery and sometimes within 6-24 hours. In practice, however, it is usual to wait three months before deciding that the hydronephrosis ande hydroureter are permanent.

$$
\begin{aligned}
& 1 \text { Lancet, 1932, 2, 983. } \\
& 2 \text { J. Obstet. Gynaec. Brit. Emp., 1935, 42, 577, } 733 . \\
& 3 \text { Amer. J. Obstet. Gynec., 1953, 65, 660. } \\
& 4 \text { J. Mich. med. Soc., 1951, 50, 41. } \\
& 5 \text { Illinois med. J., 1951, 99, 128. }
\end{aligned}
$$

\section{What is an Obsession ?}

Q.-What makes a repulsive thought an obsession? Is the mechanism fully understood?

A.- A repulsive thought, indeed any thought, is in psychiatric terminology called obsessional if it persists against the person's wish and is associated with an experience of subjective compulsion. The thought, or at least its persistence, is on quiet reflection recognized as senseless and abnormal. The psychiatric usage of the term differs from that of the vernacular, in which any persistent and troublesome mental preoccupation is often called an obsession. Certain ideas, especially those arising from sexual or aggressive tendencies, may be experienced as repulsive, though they are not obsessions in the exact meaning of the word if they are rejected only by part of the personality while another part consciously identifies itself with them and presses for their gratification. Obsessions usually reflect a mental conflict which can often be unearthed only by psycho-analysis. A good deal is known about the significance of the contents of obsessions and the type of personality predisposed to them, but their specific formal character and their origin are still not completely understood in spite of attempts by psychopathologists and neurologists to explain them.

\section{NOTES AND COMMENTS}

Ankylosing Spondylitis.-Squadron Leaders P. J. R. Nichols and D. J. E. Cheshire (R.A.F., Yealmpton, Devon) write: We would like to support the observations made by our colleagues Wyrn Parry and Milligan (Notes and Comments, November 13, p. 1180) on your expert's reply to the question on the early manifestations of ankylosing spondylitis ("Any Questions?" October 9, p. 885). This condition can be diagnosed in the early stages, frequently on the history; in the last 20 consecutive cases seen at this unit the average interval between the onset of symptoms and diagnosis was 17 months. Similarly, at this stage, the E.S.R. is of little value; in the series mentioned above, 12 cases $(60 \%)$ were diagnosed, and accepted for radiotherapy, in the presence of a normal E.S.R. In our experience with Service personnel the degree of involvement of peripheral joints tallies with that of our colleagues. Polley and Slocumb ${ }^{1}$ found that about half of a series of over 1,000 cases of ankylosing spondylitis showed temporary or permanent involvement of the peripheral joints. It is well to remember that ankylosing spondylitis is regarded by many pathologists as a disease arising not in the sacro-iliac joints but in the posterior intervertebral joints (Collins), ${ }^{2}$ and that the general teaching and attitude towards this disease have been concentrated upon the full-blown involvement of the sacro-iliac joints, a later manifestation of the condition. If we can come to regard ankylosing spondylitis as a general collagen disease usually starting in the small joints of the spine, but with pathological changes identical with rheumatoid arthritis (Collins) ${ }^{3}$ the earlier we are likely to make the diagnosis, remembering that ankylosing spondylitis may well present as an affection of the peripheral joints, with a normal E.S.R. and with normal $x$-ray pictures of the sacro-iliac joints. From this point of view the American name of rheumatoid spondylitis has much to recommend it.

REFERENCES

1 Polley, H. F., and Slocumb, C. H. (1947). Ann. intern. Med., 26, 240 2 Collins, D. H. (1949). The Pathology of Articular and Spinal Diseases, p. 315. E. Arnold and Co., London.

Correction.-In the summary of the article on "Primary Tuberculosis of the Lung " by Drs. J. H. Thomas, D. B. Morgan, and T. W. Davies (Journal, December 4, p. 1325) the second sentence should have read: "Serious complications developed in $20.3 \%$ of the active cases" (not " Previous complications ... ").

Refresher Course Books. - Copies of the first two volumes of collected articles from the Refresher Course for General Practitioners published in the Journal are still available at 25s. (postage 1s.) each. The first volume contains 55 articles and the second 60. Each article has been revised and brought up to date by its author.

Books of "Any Questions?"-The second and third books of "Any Questions?" are available at 7s. 6d. (postage 6d.) each. The third book contains a cumulative index to all the questions and answers in all three books.

These books may be obtained from the Publishing Manager, B.M.A. House, Tavistock Square, London, W.C.1, or through any bookseller.

All communications with regard to editorial business should be addressed o THE EDITOR, BRITISH MEdical JOURNal. B M.A. HOUSE. TAVISTOCK

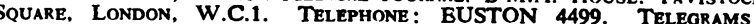
Aitiology, Westcent, London. ORIGINAL ARTICLES AND LETTERS forwarded for publication are understood to be offered to the British Medical Journal alone unless the contrary be stated.

Authors desiring REPRINTS should communicate with the Publishing Manager. B.M.A. House. Tavistock Square, W.C.1, on receipt of proofs ADVERTISEMENTS should be addressed to the Advertisement Manager, B.M.A. House. Tavistock Square, London, W.C.1 (hours 9 a.m. to 5 p.m.) TELEPHONE: EUSTON 4499. TELEGRAMS: Britmedads, Wes'cent, London MEMBERS' SUBSCRIPTIONS should be sent to the SECRETARY of the Association. TelepHONE: EUSTON 4499. TElegrams: Medisecra, B.M.A. Scotrish OfFice: 7, Drumsheugh Gardens, Edinburgh. 